\title{
An Examination of Using Self-, Peer-, and Teacher-Assessment in Higher Education: A Case Study in Teacher Education
}

\author{
Didem Kılıç \\ ${ }^{1}$ Faculty of Education, Aksaray University, Aksaray, Turkey \\ Correspondence: Didem Kılıç, Faculty of Education, Aksaray University, Aksaray, 68100, Turkey. Tel: \\ 90-382-288-2257. E-mail: didem@aksaray.edu.tr
}

Received: January 4, 2016

Accepted: January 25, 2016

Online Published: February 1, 2016

doi: 10.5539/hes.v6n1p136

URL: http://dx.doi.org/10.5539/hes.v6n1p136

\begin{abstract}
This study focuses on the process of implementing self-, peer- and teacher-assessment in teacher education in order to examine the ways of applying these assessment practices and specifically aims at finding out the level of agreement among pre-service teachers' self-, peer- and teacher-assessments of presentation performances. Pre-service teachers' presentation performances including an application of a teaching method assessed by peers and teacher and also by themselves through criteria based assessment forms. The analysis of the data revealed that there are statistically significant differences among self-, peer- and teacher-assessment scores. Peer-assessment of pre-service teachers' presentations is found to be significantly higher compared with teacher-assessment and self-assessment. With regard to the comparison of teacher-assessment scores and self-assessment scores, it is revealed that there are no significant differences between teacher- and self-assessments. In teacher training programmes beside summative approach self-, peer- and teacher-assessments can be implemented in a formative way as useful practices in developing more succesful performance, higher confidence, effective presenting skills and essential competencies required for effective teaching.
\end{abstract}

Keywords: higher education, peer-assessment, self-assessment, teacher education

\section{Introduction}

To engage students in the learning process and to encourage them to take responsibility for their own learning requires the involvement of students in the assessment process. Students' participation in the assessment process enhances the development of crucial skills such as responsibility, judgement, and autonomy, which have a considerable importance for their professional life. According to Searby and Ewers (1997) the incorporation of students into the assessment helps them thinking critically and allows them taking control of their own learning. Taking part in assessment gives substantial opportunity to students for developing self-regulating skills. Students can develop a better comprehension about their own learning process by analysing their own behaviour (De Grez, Valcke, \& Roozen, 2012). Boud and Falchikov (1989) suggest that effective learners have a realist view about their own strengths and weaknesses and they can use knowledge regarding their own learning process to direct their studying into productive directions.

Involvement of students in assessment can take place in two ways: self-assessment and peer assessment. "Self-assessment refers to the involvement of learners in making judgements about their own learning, particularly about their achievements and the outcomes of their learning" (Boud \& Falchikov, 1989, p. 529). Using self-assessment for promoting the learning of skills and abilities enable taking responsibility for one's own learning, higher quality of products, increasing understanding of problem solving (Sluijsmans, Dochy, \& Moerkerke, 1999). Boud, Lawson and Thompson (2015) suggest that without the ability of students to make effective judgments about their own work, they will not be effective learners. Development of the skill of self-assessment is becoming an increasingly important issue in many higher education institutions, and many self-assessment devices are being introduced as aids to learning (Stefani, 1994). Falchikov (1995) defines peer assessment as the process whereby groups of individuals rate their peers. Peer assessment engages students in making judgements about the work or the performance of other students (Somervell, 1993). "Peer-assessment is an arrangement for learners to consider and specify the level, value, or quality of a product or performance of other equal-status learners" (Topping, 2009, p. 20). One of the important instructional function of peer 
assessment is providing detailed feedback (Falchikov \& Goldfinch, 2000). Topping (2009) point out that peer assessment can increase variety and interest, activity and interactivity, identification and bonding, self-confidence, and empathy with others.

Self and peer-assessment are often performed together. Combining or considering self- and peer-assessment in common provide some possible advantages. Peer-assessment can help self-assessment. Evaluating the performance or outcomes of others give students the opportunity to gain insight about their own performance (Bostock, 2001). Self- and peer-assessment provide opportunity to promote self-awareness by means of feedback from multiple perspectives (Saito \& Fujita, 2004). Feedback enable students to enhance their performance by realizing their own gaps and by reducing their mistakes. Students find the opportunity to deepen their understanding on learned topics with the help of feedback. By providing feedback in a forward looking way students improve their future performance, since feedforward approach enable to offer appropriate suggestions and guidance for helping students to remediate their learning process (Osado, Merlo, \& Campo, 2013). Feedforward helps students to achieve their goals by providing chance to make positive changes in the future. Incorporation of feedback and feedforward with self- and peer-assessment promote students' learning by developing critical thinking skills. Researchers specify the strengths of using self- and peer-assessment that (a) stimulate students and promote them to paticipate actively in learning; (b) causes more intended and effective learning; (c) allow students to become self-sufficient in learning; (d) enables students to think deeply and to learn constructively criticising (Sluijsmans et al., 1999).

Self- and peer-assessment can be either summative, thus concentrating on judging learning results to be correct or incorrect or assigning a quantitative grade, or formative, if they concentrate on in-depth qualitative assessment of different kinds of learning results (Topping, 2003). The distinctions between formative and summative assestments based on the purposes of assessment. Formative assessment emphasized as "assessment for learning", which is known to improve learning and summative assessment is stated as "assessment of learning", since it aims to summarise the level of learning. Sometimes it can be difficult to differentiate between formative and summative assessment, since the same assessment tasks may be used for both summative and formative purposes (Earle, 2014). Where applications of self-assessment and peer-assessment were mostly used for formative purposes, combinations of these forms with co-assessment work out well for summative assessments (Sluijsmans et al., 1999). Similarly and Somervell (1993) suggest that self- and peer-assessment can be used for summative purposes as part of the co-assessment by giving the teacher the power to make the final decision about a process or a product. The combination of self-, peer- and co-assessment enables teachers and students to work together in a constructive way and, as a result, they come to higher levels of understanding by negotiation. It was concluded that the use of self-, peer- and co-assessment simultaneously can be effective also for removing the barrier between student and teacher, and leads to greater motivation and deep learning (Somervell, 1993).

Results of the research investigating the perceptions of students about peer-assessment show that a very positive attitude towards using peer assessment (De Grez et al., 2012). Researchers report that implementing self- and/or peer-assessment have positive influences on students' perceptions. When self-assessment incorporated into the learning process in an educational environment, the level of students' motivation can be strengthen (Dochy, Segers, \& Sluijsmans, 1999). Orsmond, Merry and Reiling (1996) revealed that students were pleased with performing the peer assessment task and thought that it was contributing to their learning. Results of another research showed that both the teachers and the students had mostly positive experiences of the assessment processes (Lindblom-Ylänne, Pihlajamäki, \& Kotkas, 2006). On the other hand students found that criticising their friends was difficult (Sluijsmans, Brand-Gruwel, \& van Merriënboer, 2002). Research findings reveal that some students hesitate to grade their classmates and they do not feel comfortable when evaluating a fellow student. Students found grading to each other risky and unfair, and they also doubt the objectivity of peer assessment (Sluijsmans et al., 2002). Research findings revealed that being objective is difficult for students and they do not feel comfortable when critiquing another student (Hanrahan \& Isaacs, 2001).

The validity and reliability of self- and peer-assessments are found debatable since the social and cognitive processes can influence the accuracy of these assessment procedures. Topping (2009) specifies that bond of friendship, sympathy or antipathy, or popularity of individuals can be effective on peer assessment. Another reason is seen as student tolerance for preserving friendships and not to give rise to a conflict (Friedman, Cox, \& Maher, 2008). On the one hand students consider peer assessment beneficial for their own learning process, on the other hand students are doubtful about the value of peer comments (Orsmond et al., 1996) and they do not always believe that their peers will mark them fairly (McDowell, 1995). Student success and grade level are factors, which have an effect on the reliability of self-assessment (Dochy et al., 1999; Friedman et al., 2008). Boud and Falchikov (1989) stated that more succesful students tend to underestimate their performance, whereas 
less succesful students have a tendency to overestimate their own performance. Dochy et al. (1999) further reported that at different grade levels, students' self-assessment skills seemed to improve, because advanced students could evaluate their performance more accurate than novices. According to a review of research on self-assessment, Dochy et al. (1999) reported that students are quite accurate in grading their own learning outcomes. In contrast, however, according to Topping (2003), self-assessed grades tend to be higher than teacher grades (Friedman et al., 2008).

Researchers offer several suggestions regarding these problems (Lindblom-Ylänne et al., 2006): there is evidence that application of specific criteria, transparent assessment processes, clear instructions and training improvement of students' assessment skills, and also that the use of a scoring matrix may be helpful. Disadvantages of peer assessment, such as friendship marking (resulting in over-marking) and decibel marking (where individuals dominate groups and get the highest marks), are mostly solved by using combinations of peer-assessment with self- and teacher- assessment (Pond, Ul-Haq, \& Wade, 1995; Sluijsmans et al., 1999). In the current study, which builds on previous work in other countries, combination of self-, peer- and teacher-assessment implemented by using a scoring matrix to find out particularly the agreement of these assessment procedures.

Since self- and peer-assessment practices enhance critical appraisal skills, provide feedback, and foster attendance, the use of these assessment tasks in higher education has been supported by researchers and educators have been questing for the ways to use them effectively in their courses. Sluijsmans et al. (2002) suggest that alternative assessment procedures including the use of peer-assessment can have a positive effect on the development of pre-service teachers' own assessment skills. They emphasize that critical assessment of the performances of peers is considerably important in the teacher-training context. Hill (2007) also argues that teacher education should enable pre-service teachers to develop the skills to critically examine the nature of teaching. The incorporation of self- and peer-assessment in the educational context gives opportunity to pre-service teachers examining their pedagogical potential at first hand (Lynch, McNamara, \& Seery, 2012). Within this theoretical and empirical framework, this study focuses on the process of implementing self-, peerand teacher-assessment in teacher education in order to examine the ways of applying these assessment practices and to explore the benefits of the procedures. The research question to specify this main concern was "What is the level of the agreement among pre-service teachers' self-, peer-, and teacher-assessments?"

\section{Method}

\subsection{Participants}

The participants in this study were fifteen pre-service teachers enrolled in an applied course "Principles and Methods of Teaching" at a state university in Turkey. Of these, nine were female and six were male students with the average age of 19. All students enrolled in the course were in their second year and all of them had experience on self- and peer-assessment. As part of their one of the former course, they were instructed theoretically about alternative assessment procedures including self- and peer-assessment. Moreover they had experience on using self- and peer-assessment tools practically in another previous course conducted by the researcher. So the participants of the study had both theoretical and practical experience on self- and peer-assessment procedures. Initially, 23 students participated in the study, however some students missed the assessment sessions and 8 students dropped out.

\subsection{Procedures}

The "Principles and Methods of Teaching" course aims at students to comprehend the fundamental concepts and principles related to teaching, to comprehend instructional strategies and methods and also to use them effectively. As a formal part of the course, each of the pre-service teachers were expected to deliver a presentation including an application of a teaching method. The presentations given during the course lasted approximately 30 minutes and every pre-service teacher presented a subject content by applying a teaching method. An example of teaching method application was demonstrated and explained by the researcher before the presentations. Also the participants were instructed about effective presentation skills by the researcher as part of their communication course.

Following each presentation, pre-service teachers were asked to complete an assessment form (see Appendix) containing criteria about presenting performance. Presenting performance of pre-service teachers was assessed using three criteria based assessment forms; self-, peer- and teacher-assessment forms. These forms of assessment based on divergent competencies required for effective teaching such as comprehensible expression; effective application; being planned and controlled; management of time; using body language, gesture and facial expression efficiently. While developing the assessment form the criteria have been identified after 
reviewing related research literature on the characteristics to be included in the presentation performance for effective teaching. Moreover by considering pre-service teachers' views a total of five criteria for presentation performance decided. These specific criteria related with the objectives of the course were organized in a scoring matrix with informative instructions in order to provide effective and objective assessment tasks. Gueldenzoph and May (2002) recommend that the specific criteria linked with the objectives of the course, and according to Levi and Cadiz (1998) specific criteria related to the aims of the course may increase the accuracy of assessment.

Pre-service teachers graded the presentations on the aforementioned five assessment criteria using the scoring matrix ranged from 1 to 5 (1 point for unsuccessful, 2 point for unsatisfactory, 3 point for improvement necessary, 4 point for successful, 5 point for exemplary), yielding a maximum possible score of 25 points. These performance levels, which differ from 1 to 5 were explained to the pre-service teachers before they graded their fellows. Each presentation was assessed from 14 different peers. Dannefer et al. (2005) concluded that at least six peers are needed to achieve a moderate reliability when assessing professional competencies. As part of the current research design, participants were also asked to grade their own presentation performance on the basis of the criteria-based assessment form.

The self-, peer- and teacher-assessments were carried out independently of each other. Administration of the assessment tasks lasted for five weeks. At the beginning of the administrations, the assessment criteria were specified and known by the participants. Also participants did not inform about their total scores during the presentation sessions, they were not given feedback about their performance until after all the sessions completed. By this means the possible developments of later presentations in comparison with earlier presentation performances had tried to keep minimum. After all presentation sessions finished the total score for each participant was calculated. For grading each of the participant's performance, the mean score of the peer-assessment scores were added with self-assessment score and teacher-assessment score. In the study besides making contribution to preservice teachers' assessment skills by means of using assessment tasks for formative purpose, because of the main design was summative assessment, participants' total scores were considered with their final grades. The weighting of the assessment task was $30 \%$ of the course grade. And the participants were informed about this percentage of weighting at early on the course semester.

\subsection{Analysis}

The data obtained from the administration of the assessment forms were entered into SPSS for data analysis. Descriptive statistics, including means, skewness and kurtosis were determined for the pre-service teachers' self-, peer-, and teacher-assessment scores. The values of skewness and kurtosis showed that the data violated the assumption of normality. Moreover the Shapiro-Wilk test was run in order to determine if the data met the normality assumption. The results showed that data for self-, peer- and teacher-assessment did not conform to normality (Shapiro-Wilk for self-assessment data $=0.839, \mathrm{df}=15, p=.012$, Shapiro-Wilk for peer-assessment data $=0.820, \mathrm{df}=15, p=.007$, and Shapiro-Wilk for teacher-assessment data $=0.862, \mathrm{df}=15, p=.025$ ). Therefore, the data were treated as non-parametric. For the research question concerning the level of the agreement among pre-service teachers' self-, peer-, and teacher-assessments, the Friedman ANOVA test was employed to analyze whether the differences among self-, peer- and teacher-assessments are statistically significant. For post-hoc comparisons, Wilcoxon signed-rank test was used. The effect sizes were reported.

\section{Results}

Descriptive statistics including means, skewness and kurtosis for self-, peer- and teacher-assessment scores summarized in Table 1. When mean scores of the assessments were compared, it can be seen in Table 1 that peer-assessment scores of the pre-service teachers with a mean score of 22.53 appeared to be higher than mean scores of self-assessment $(M=19.60)$ and teacher-assessment $(M=20.00)$.

Table 1. Descriptive statistics for self-, peer- and teacher-assessment scores

\begin{tabular}{llll}
\hline & Self-assessment & Peer-assessment & Teacher-assessment \\
\hline Mean & 19.60 & 22.53 & 20.00 \\
Skewness & -1.743 & -1.011 & -1.440 \\
Std. Error of Skewness & 0.580 & 0.580 & 0.580 \\
Kurtosis & 3.819 & -0.035 & 1.930 \\
Std. Error of Kurtosis & 1.121 & 1.121 & 1.121 \\
\hline
\end{tabular}


In order to determine that these differences among mean scores are statistically significant, Friedman's analyses of variance test was conducted. Summary of the test results comparing mean scores of pre-service teachers' self-, peer- and teacher-assessment is presented in Table 2.

Table 2. Friedman's ANOVA test summary for comparing pre-service teachers' self-, peer- and teacher-assessments

\begin{tabular}{llcccc}
\hline & & N & Chi-Square & df & $p$ \\
\hline Self-assessment & - & & & & \\
Peer-assesment & - & 15 & 9.529 & 2 & .009 \\
Teacher-assessment & & & & & \\
\hline
\end{tabular}

Results of the Friedman's analyses of variance test indicated that there was a significant difference among self-, peer-, and teacher-assessment scores (Chi-Square $=9.529, p<.05$ ). The mean rank value of the peer-assessment (2.60) is found to be higher than the mean ranks for self-assessment (1.70) and teacher-assessment (1.70). To find out the source of this difference, Wilcoxon signed-rank test was run and the summary of the test results is presented in Table 3. Because of this comparisons gave rise to three tests (Test 1: peer-assessment compared to self-assessment; Test 2: self-assessment compared to teacher-assessment; Test 3: peer-assessment compared to teacher-assessment), the critical level of significance was considered as $0.05 / 3=0.017$.

Table 3. Wilcoxon signed rank test summary for comparing pre-service teachers' self-, peer- and teacher-assessments

\begin{tabular}{|c|c|c|c|c|c|c|}
\hline & & $\mathrm{N}$ & $\begin{array}{l}\text { Mean } \\
\text { Rank }\end{array}$ & $\begin{array}{l}\text { Sum of } \\
\text { Ranks }\end{array}$ & $z$ & $p$ \\
\hline \multirow{4}{*}{$\begin{array}{l}\text { Peer-assessment- } \\
\text { Self assessment }\end{array}$} & Negative ranks & 2 & 3.00 & 6.00 & $-2.781^{a}$ & .005 \\
\hline & Positive ranks & 11 & 7.73 & 85.00 & & \\
\hline & Ties & 2 & & & & \\
\hline & Total & 15 & & & & \\
\hline \multirow{4}{*}{$\begin{array}{l}\text { Self-assessment- } \\
\text { Teacher assessment }\end{array}$} & Negative ranks & 7 & 7.57 & 53.00 & $-.531^{\mathrm{b}}$ & .596 \\
\hline & Positive ranks & 6 & 6.33 & 38.00 & & \\
\hline & Ties & 2 & & & & \\
\hline & Total & 15 & & & & \\
\hline \multirow{4}{*}{$\begin{array}{l}\text { Peer-assessment- } \\
\text { Teacher assessment }\end{array}$} & Negative ranks & 0 & 0 & 0.00 & $-2.823^{\mathrm{a}}$ & .005 \\
\hline & Positive ranks & 10 & 5.50 & 55.00 & & \\
\hline & Ties & 5 & & & & \\
\hline & Total & 15 & & & & \\
\hline
\end{tabular}

Results of the Wilcoxon signed rank test analysis indicated that there was a significant difference between peerand self-assessment scores, $z=-2.781, p<.017$. When the mean rank and sum of ranks were considered, it is concluded that the peer-assessment was significantly higher than self-assessment. The effect size was found to be .51 (it is above Cohen's benchmark of .5) and this represents a large effect (Field, 2005). It can be also seen from the Table 3 that there was a significant difference between peer- and teacher-assessment scores, $z=-2.823, p<$ .017. According to the mean rank and sum of ranks the difference was in favor of the positive ranks. This means the peer-assessment was significantly higher than teacher-assessment and the effect size was calculated as .52 and this represents a large effect. In addition, results of the Wilcoxon signed rank test analyses showed that the difference between the mean scores of self-assessment $(M=19.60)$ and teacher-assessment $(M=20.00)$ was not statistically significant, $z=-.531, p>.017$. 


\section{Discussion and Conclusions}

Self- and peer-assessment have considerable importance particularly for pre-service teachers, since these assessment procedures give opportunity for the development of the skills of self-regulating, critical thinking, and problem solving, which are essential for teachers. Sluijsmans et al. (2002) suggest that training students about critical evaluation of the performances of peers is important, especially in the teacher-training context. In this research self-, peer-, and teacher-assessment tasks were performed with pre-service teachers' and the level of agreement among assessments was revealed.

The results regarding the peer-assessment showed significant difference with self-assessment and teacher-assessment. Peer-assessment of pre-service teachers' performances is found to be significantly higher compared with teacher-assessment and self-assessment. One of the possible reason of this result could be the approach to the assessment carried out within the context of the study. Summative approach to assessment could be cause for high peer-ratings. The finding that the peer-assessment scores are, mostly, higher than the marks given by teachers is consistent with the results reported in the literature (Magin \& Helmore, 2001; Rudy, Fejfar, Griffith, \& Wilson, 2001). Besides, the finding that reveal significant difference between peer- and teacher-assessment show variance with some of the other studies from varying disciplines, which have found close correspondence between peer and teacher marks (Falcikov, 1995; Freeman, 1995; Stefani, 1994). According to another finding of this study, the score reported by peers is significantly higher compared with the self-assessments, which contrasts with the results of the research carried out by Falchikov (1991, as cited in Dochy et al., 1999). Falchikov showed that there was no tendency to over- or under-mark when self ratings were compared with peer ratings. Differently from Falchikov, Rudy et al. (2001) revealed that peer-ratings were higher than self-ratings. The consensus view has been that, where there is a difference, students tend to under-assess themselves in comparison with their peers (Lejk \& Wyvill, 2001, p. 559).

With regard to the comparison of teacher-assessment scores and self-assessment scores, it is revealed that there are no significant differences between teacher- and self-assessments. The results concerning self-assessment scores showed that pre-service teachers had realistic perceptions of their own abilities and made rational judgements. Pre-service teachers felt confidence in grading their own performance while they could take responsibility of their own learning. Participants in the study were familiar with self-assessment tasks and they were experienced about evaluating themselves through the given criteria. Sluijsmans et al. (1999) stated that the ability of students to rate themselves improves within their total experience of educational life. More experienced students tend to be more accurate in their self-assessment than less experienced students (Lejk \& Wyvill, 2001).

As a conclusion of this study, the differences among pre-service teachers' self-, peer- and teacher-assessment scores were revealed. Also in line with the results, the possible sources of these differences were discussed. Since the quantitative research methodology carried-out in accordance with the research problem, the results of the current study ensued in frame of this methodological design. It might be worthy of inquiry in a follow-up study to interview with the participants for a depth analyses in order to suggest detailed reasons on differences among self-, peer-, and teacher-assessment.

Overall, it can be concluded that related literature establish positive findings concerning the use of self- and peer-assessment in educational practice, despite their limitations. According to another research results most of the students think that these assessment processess are challenging, time consuming, and socially inconventient, but also significant at improving the quality of learning outcomes and developing other skills and abilities (Topping, Smith, Swanson, \& Elliot, 2000). In teacher training programmes beside summative approach self-, peer- and teacher-assessments can be implemented in a formative way as useful practices in developing higher learning performance, higher presentation confidence and essential competencies required for effective teaching. Organizing self- and peer-assessment for obtaining more reliable and valid outcomes can be possible by providing effective feedback, clarifying the purpose and expectations, providing practice and examples. When pre-service teachers can critically evaluate themselves and the performances of their peers accurately and objectively, they will be better prepared to demonstrate objective attitudes in their future professional career. Thus, more frequent use of self- and peer-assessments in assessment and evaluation process and investigation of their outcomes are believed to make important contributions to teacher education. 


\section{References}

Bostock, S. (2001). Student peer assessment. Higher education academy. Retrieved from https://www.cs.auckland.ac.nz/courses/compsci747s2c/lectures/paul/Student_peer_assessment___Stephen_ Bostock.pdf

Boud, D., \& Falchikov, N. (1989). Quantitative studies of self-assessment in higher education: A critical analysis of findings. Higher Education, 18, 529-549. http://dx.doi.org/10.1007/BF00138746

Boud, D., Lawson, R., \& Thompson, D. G. (2015). The calibration of student judgement through self-assessment: Disruptive effects of assessment patterns. Higher Education Research \& Development, 34(1), 45-59. http://dx.doi.org/10.1080/07294360.2014.934328

Dannefer, E., Henson, L., Bierer, S., Grady-Weliky, T., Meldrum, S., ... Nofziger, A. (2005). Peer assessment of $\begin{array}{llll}\text { professional } & \text { competence. }\end{array}$ http://dx.doi.org/10.1111/j.1365-2929.2005.02193.x

De Grez, L., Valcke, M., \& Roozen, I. (2012). How effective are self- and peer-assessment of oral presentation skills compared with teachers' assessment? Active Learning in Higher Education, 13(2), 129-142. http://dx.doi.org/10.1177/1469787412441284

Dochy, F., Segers, M., \& Sluijsmans, D. (1999). The use of self-, peer- and co-assessment in higher education: A review. Studies in Higher Education, 24(3), 331-350. http://dx.doi.org/10.1080/03075079912331379935

Earle, S. (2014). Formative and summative assessment of science in English primary schools: Evidence from the Primary Science Quality Mark. Research in Science \& Technological Education, 32(2), 216-228. http://dx.doi.org/10.1080/02635143.2014.913129

Falchikov, N. (1995). Peer feedback marking: Developing peer assessment. Innovations in Education \& Training International, 32(2), 175-187. http://dx.doi.org/10.1080/1355800950320212

Falchikov, N., \& Goldfinch, J. (2000). Student peer assessment in higher education: A meta-analysis comparing peer and teacher marks. Review of Educational Research, 70(3), 287-322. http://dx.doi.org/10.3102/00346543070003287

Field, A. (2005). Discovering statistics using SPSS (2nd ed.). London: Sage Publications.

Freeman, M. (1995). Peer assessment by groups of group work. Assessment \& Evaluation in Higher Education, 20(3), 289-300. http://dx.doi.org/10.1080/0260293950200305

Friedman, B. A., Cox, P. L., \& Maher, L. E. (2008). An expectancy theory motivation approach to peer assessment. Journal of Management Education, 32(5), 580-612. http://dx.doi.org/10.1177/1052562907310641

Gueldenzoph, L. E., \& May, G. L. (2002). Collaborative peer evaluation: Best practices for group member

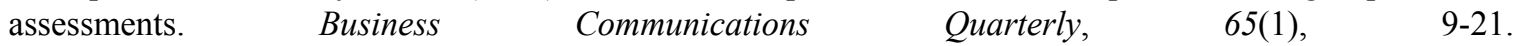
http://dx.doi.org/10.1177/108056990206500102

Hanrahan, S. J., \& Isaacs, G. (2001). Assessing self- and peer-assessment: The students' views. Higher Education Research \& Development, 20(1), 53-70. http://dx.doi.org/10.1080/07294360123776

Hill, D. (2007). Critical teacher education, new labour, and the global project of neoliberal capital. Policy Futures in Education, 5(2), 204-225. http://dx.doi.org/10.2304/pfie.2007.5.2.204

Lejk, M., \& Wyvill, M. (2001). The effect of the inclusion of selfassessment with peer assessment of contributions to a group project: A quantitative study of secret and agreed assessments. Assessment \& Evaluation in Higher Education, 26(6), 551-561. http://dx.doi.org/10.1080/02602930020022291

Levi, D., \& Cadiz, D. (1998). Evaluating team work on student projects: The use of behaviorally anchored scales to evaluate student performance (ERIC Document Reproduction Service, ED 424250). Washington, D.C.: Educational Resources Information Center.

Lindblom-Ylänne, S., Pihlajamäki, H., \& Kotkas, T. (2006). Self-, peer- and teacher-assessment of student essays. Active Learning in Higher Education, 7(1), 51-62. http://dx.doi.org/10.1177/1469787406061148

Lynch, R., McNamara, P. M., \& Seery, N. (2012). Promoting deep learning in a teacher education programme through self- and peer-assessment and feedback. European Journal of Teacher Education, 35(2), 179-197. http://dx.doi.org/10.1080/02619768.2011.643396

Magin, D., \& Helmore, P. (2001). Peer and teacher assessments of oral presentation skills: How reliable are 
they? Studies in Higher Education, 26(3), 287-298. http://dx.doi.org/10.1080/03075070120076264

McDowell, L. (1995). The impact of innovative assessment on student learning. Innovations in Education \& Training International, 32(4), 302-313. http://dx.doi.org/10.1080/1355800950320402

Orsmond, P., Merry, S., \& Reiling, K. (1996). The importance of marking criteria in the use of peer assessment. $\begin{array}{llll}\text { Assessment \& Evaluation in Higher Education, 21(3), 239-249. } & \text {. }\end{array}$ http://dx.doi.org/10.1080/0260293960210304

Osado, A. G., Merlo, L. F. S., \& Campo, M. H. D. (2013). Formative assessment in a chemistry course through feedback and feed-forward strategies. INTED2013 Proceedings, 3852-3860.

Pond, K., Ul-haq, R., \& Wade, W. (1995). Peer review: A precursor to peer assessment. Innovations in Education \& Training International, 32(4), 314-323. http://dx.doi.org/10.1080/1355800950320403

Rudy, D. W., Fejfar, M. C., Griffith, C. H. III, \& Wilson, J. F. (2001). Self- and peer- assessment in a first-year communication and interviewing course. Evaluation \& The Health Professions, 24(4), 436-445. http://dx.doi.org 10.1177/016327870102400405

Saito, H., \& Fujita, T. (2004). Characteristics and user acceptance of peer rating in EFL writing classrooms. Language Teaching Research, 8, 31-54. http://dx.doi.org/10.1191/1362168804lr133oa

Searby, M., \& Ewers, T. (1997). An evaluation of the use of peer assessment in higher education: A case study in the school of music, Kingston University. Assessment \& Evaluation in Higher Education, 22(4), 371-383. http://dx.doi.org/10.1080/0260293970220402

Sluijsmans, D., Brand-Gruwel, S., \& van Merriënboer, J. J. G. (2002). Peer assessment training in teacher education: Effects on performance and perceptions. Assessment \& Evaluation in Higher Education, 27(5), 443-454. http://dx.doi.org/10.1080/0260293022000009311

Sluijsmans, D., Dochy, F., \& Moerkerke, G. (1999). Creating a learning environment by using self-, peer- and co-assessment. Learning Environments Research, 1, 293-319. http://dx.doi.org/10.1023/A:1009932704458

Somervell, H. (1993). Issues in assessment, enterprise and higher education: The case for self, peer and collaborative assessment. Assessment \& Evaluation in Higher Education, 18(3), 221-233. http://dx.doi.org/10.1080/0260293930180306

Stefani, L. A. J. (1994). Peer, self and tutor assessment: Relative reliabilities. Studies in Higher Education, 19(1), 69-75. http://dx.doi.org/10.1080/03075079412331382153

Topping, K. (2003). Self- and peer assessment in school and university: Reliability, validity and utility. In M. Segers, F. Dochy, \& E. Cascallar (Eds.), Optimising new modes of assessment: In search of qualities and standards (pp. 55-87). Dordrecht: Kluwer Academic. http://dx.doi.org/10.1007/0-306-48125-1_4

Topping, K. J. (2009). Peer assessment. Theory Into Practice, 48(1), 20-27. http://dx.doi.org/10.1080/00405840802577569

Topping, K. J., Smith, E. F., Swanson, I., \& Elliot, A. (2000). Formative peer assessment of academic writing between postgraduate students. Assessment \& Evaluation in Higher Education, 25(2), 149-169. http://dx.doi.org/10.1080/713611428 


\section{Appendix}

\section{The Assessment Form}

Please assign a value between 1 and 5 in terms of presentation performance by considering carefully on each listed criteria.

\begin{tabular}{|c|c|c|c|c|c|}
\hline & 1 & 2 & 3 & 4 & 5 \\
\hline & Unsuccessful & Unsatisfactory & $\begin{array}{l}\text { Improvement } \\
\text { necessary }\end{array}$ & Successful & Exemplary \\
\hline \multicolumn{6}{|l|}{ Comprehensible expression } \\
\hline \multicolumn{6}{|l|}{ Effective application } \\
\hline \multicolumn{6}{|l|}{ Being planned and controlled } \\
\hline \multicolumn{6}{|l|}{ Management of time } \\
\hline \multicolumn{6}{|l|}{$\begin{array}{l}\text { Using body language, gesture } \\
\text { and facial expression efficiently }\end{array}$} \\
\hline
\end{tabular}

\section{Copyrights}

Copyright for this article is retained by the author, with first publication rights granted to the journal.

This is an open-access article distributed under the terms and conditions of the Creative Commons Attribution license (http://creativecommons.org/licenses/by/3.0/). 